\title{
ANAESTHESIA FOR MICROSURGERY OF THE LARYNX
}

(A new method)

Edward Carden, M.A., M.B., B.ChiR., C.R.C.P. (c) ${ }^{*}$ and William Crutchfield, M.D. $\dagger$

Microsurgery of the larynx using direct laryngoscopy, with or without the operating microscope, is becoming an increasingly popular technique in the armamentarium of the otorhinolaryngologist. A great variety of techniques of anaesthesia have been developed for these procedures, far too many to be documented here, but even though the proponents of these techniques are happy with them, they all have some drawbacks. Either they provide a decreased field of vision for the surgeon or they require an unusual degree of surgeon-anaesthetist co-operation for the operation to be accomplished smoothly without hazard to the patient.

In order to improve both operating and anaesthetic conditions, three new and interesting techniques have recently been published. ${ }^{1-4}$ One technique ${ }^{1,2}$ employs an oxygen jet attached to the blade of the suspension laryngoscope, through which oxygen is administered through the cords when the laryngoscope blade is correctly positioned. This causes intermittent positive pressure ventilation of the lungs with a mixture of oxygen and air. This is because the trachea acts as a venturi tube as the oxygen jets down into it, and therefore air is entrained.

The second technique ${ }^{3}$ recently described approaches the problem in a slightly different way. It makes use of an oxygen jet placed in the trachea through the crycothyroid membrane, the jet consisting of a 16-gauge plastic cannula aimed caudally. By intermittently firing oxygen from this jet down into the trachea, positive pressure ventilation of the lungs can be accomplished as with the previous technique. Both these methods have drawbacks ${ }^{2.3}$ which would tend to eliminate them from universal use.

The third technique ${ }^{4}$ employs a tube of approximately 15 French gauge which passes via the nose and ends $2-3 \mathrm{~cm}$ below the cords. As before, an intermittent jet of oxygen from the end of the tube causes intermittent inflation of the lungs. This technique seems to be a great improvement over the earlier mentioned ones, but has the following possible drawbacks. The inflation pressure is not known, and the tube is floating free between the cords and may get in the surgeon's way or could cause damage to tracheal mucosa from the force of the oxygen jet emitted from the end. Also because of the small size of the jet, some air entrainment would be expected.

Our idea was to produce a system which would effectively ventilate the patient with known pressures and which would anchor the anaesthetic equipment around the area of the cords so that it would not get into the surgeon's way. Also by

Department of Anesthesiology and Department of Otolaryngologył, University of North Carolina School of Medicine, Chapel Hill, North Carolina 27514, U.S.A.

Requests for reprints should be sent to: Dr. Edward Carden, Department of Anesthesiology, North Carolina Memorial Hospital, Chapel Hill, North Carolina 27514. 


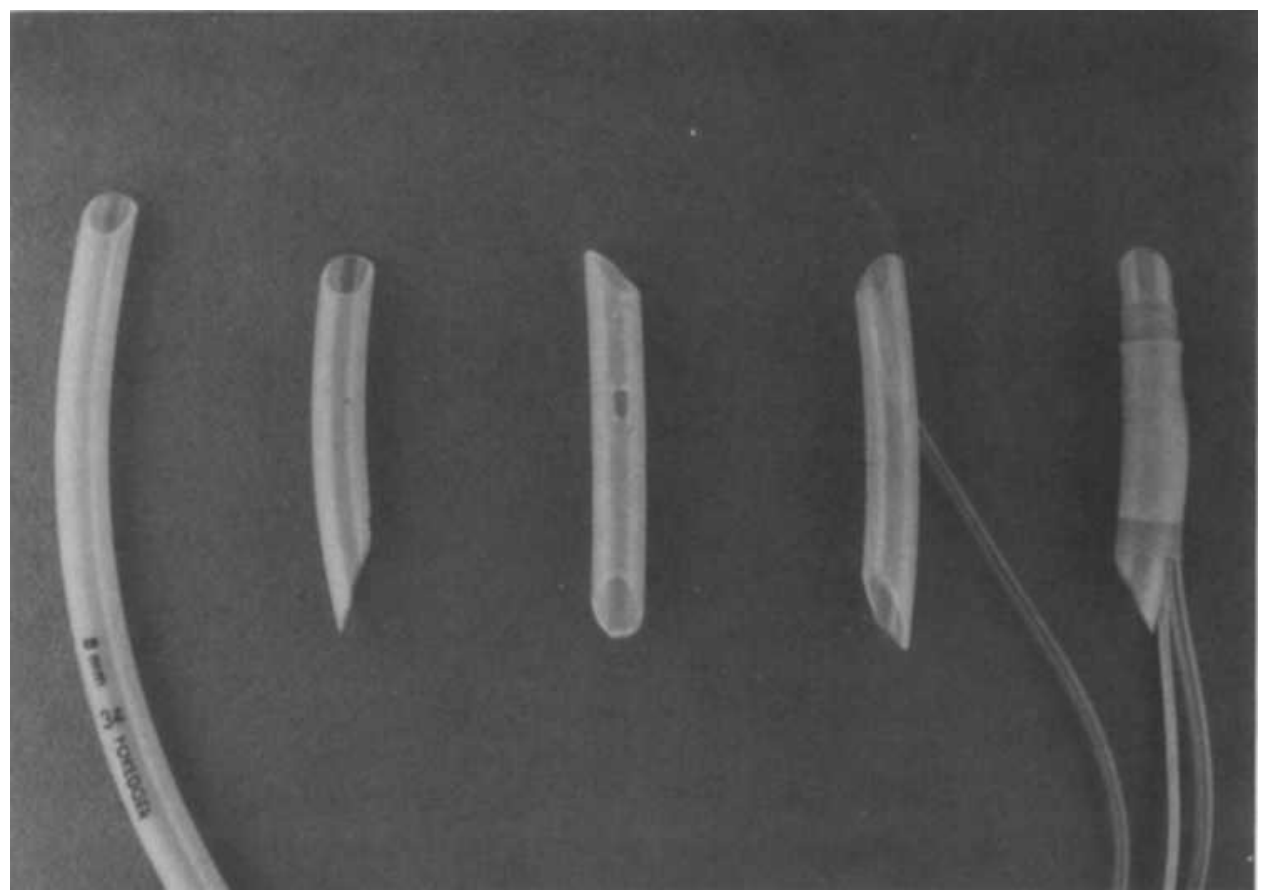

Figure 1. Step by step of the manufacture of the special tracheal tube. 1. An $8 \mathrm{~mm}$ tracheal tube. 2. The tube cut to $2 \%^{\prime \prime}$ in length. 3. A hole cut in the wall. 4 . The oxygen jet tube inserted through the hole. 5 . The whole device held together with a latex cuff.

increasing the size of the jet the amount of air entrainment could be minimized and, likewise, the likelihood of inhalation of blood or debris into the patient's lungs.

\section{Materials AND Method}

For this new technique a special tube was constructed (see Figures 1 and 2). Conventional $7 \mathrm{~mm}, 7 \frac{1}{2} \mathrm{~mm}, 8 \mathrm{~mm}$, and $9 \mathrm{~mm}$ plastic tracheal tubes without cuffs were adapted simply with a scalpel. The oxygen jet tubing was taken from an intravenous infusion set (internal diameter $0.10^{\prime \prime}$ ), and projected approximately 8 to $10 \mathrm{~mm}$ into the lumen of the tube, pointing distally to act as an oxygen jet. An inflatable rubber cuff was then placed over the tube and the oxygen jet tubing, holding the two tubes together by its elasticity. The cuff was positioned so that the cuff inflating tube lay next to the oxygen jet tube. A silk suture was inserted through the tapered end of the long side to approximate the two small tubes to the tapered proximal end of the tracheal tube. Initially, a long length of suture was left attached so that it could be used to pull on this tube to help remove it from the trachea after the operation. This was later found to be unnecessary and was then removed. An applicator which could be used to place this device into the trachea was made from stainless steel (Figure 3 ) and designed so that a circular bulge made of brass was fixed onto it to serve to locate the tracheal tube on the shaft, but yet to pass easily in and out of the vocal cords. A system was purchased with which 

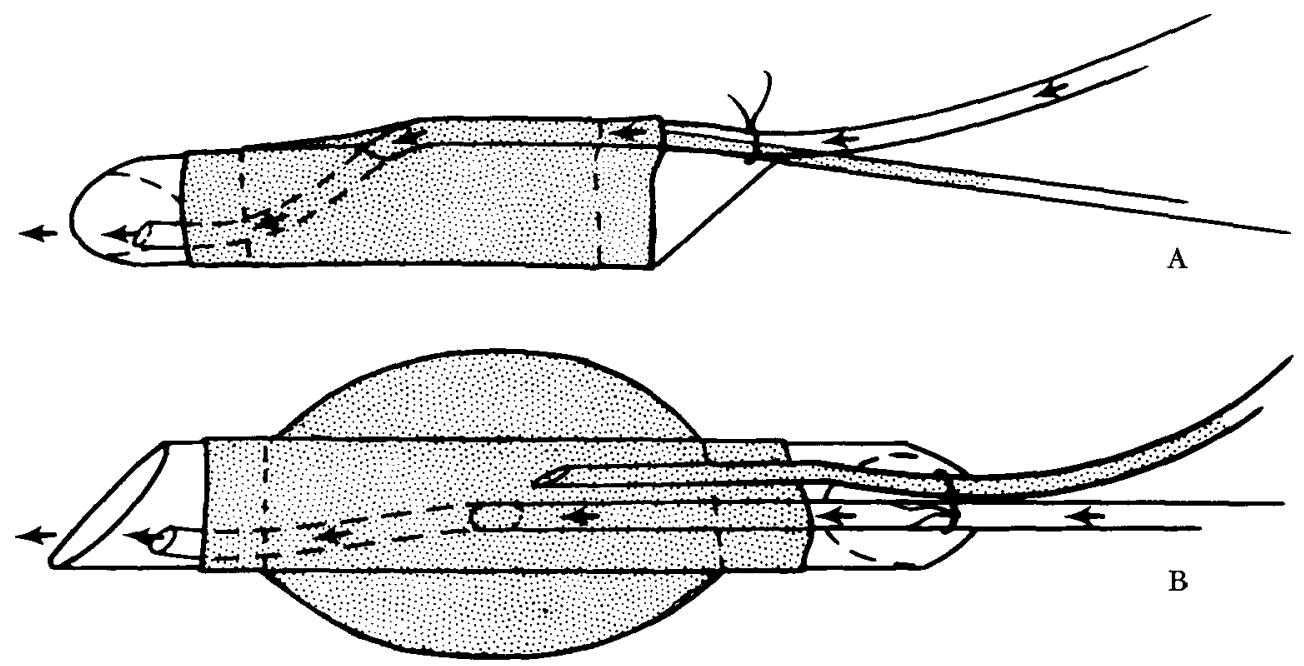

Figure 2. Schematic drawings of the special tracheal tube (A) from the side cuff down and (B), from above cuff inflated.

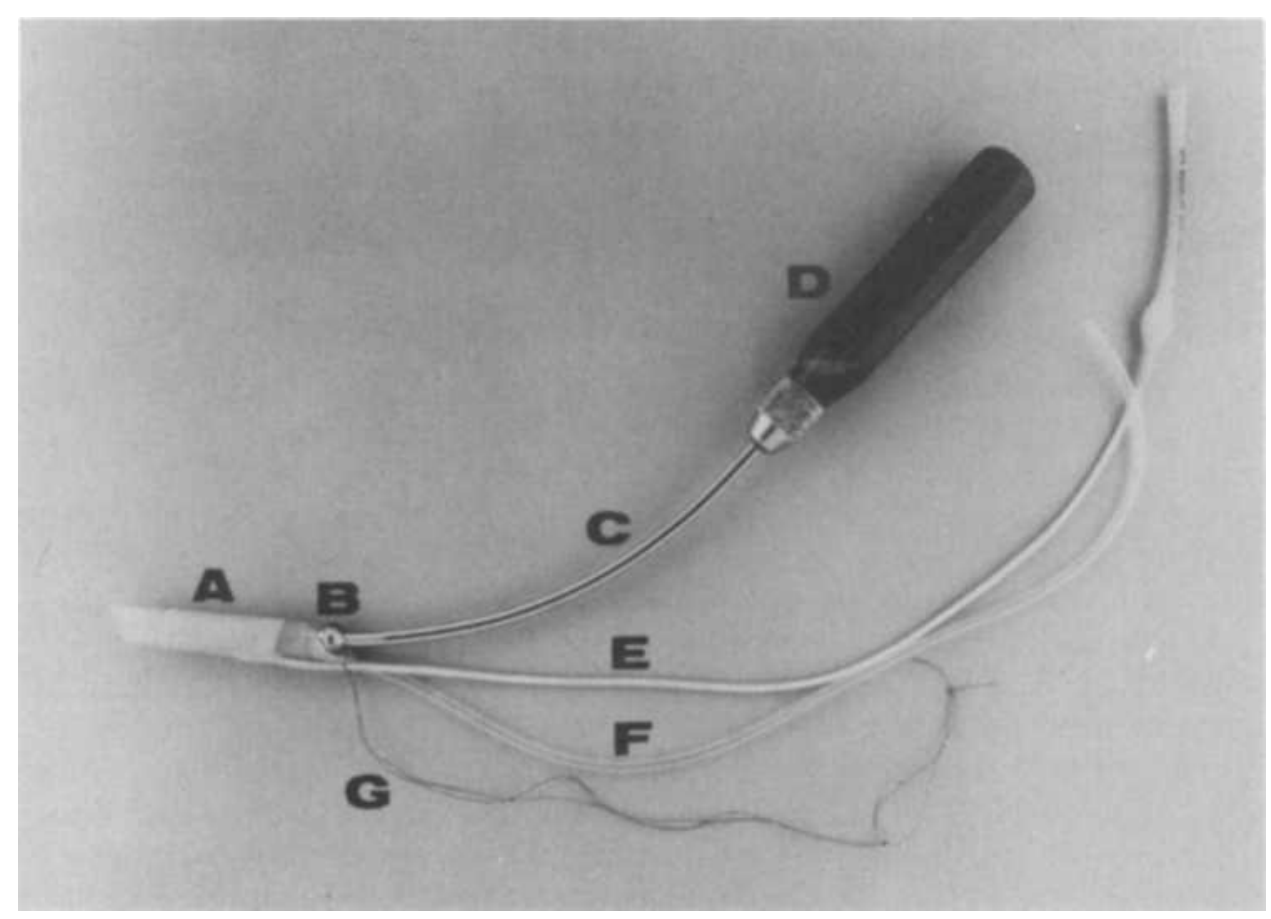

Figure 3. The special tracheal tube mounted on the obturator. Shown are: (A) Tracheal tube. (B) Brass bulge. (C) Obturator shaft. (D) Obturator handle. (E) Cuff inflation tube, (F) Oxygen jet tube. (G) Suture. 


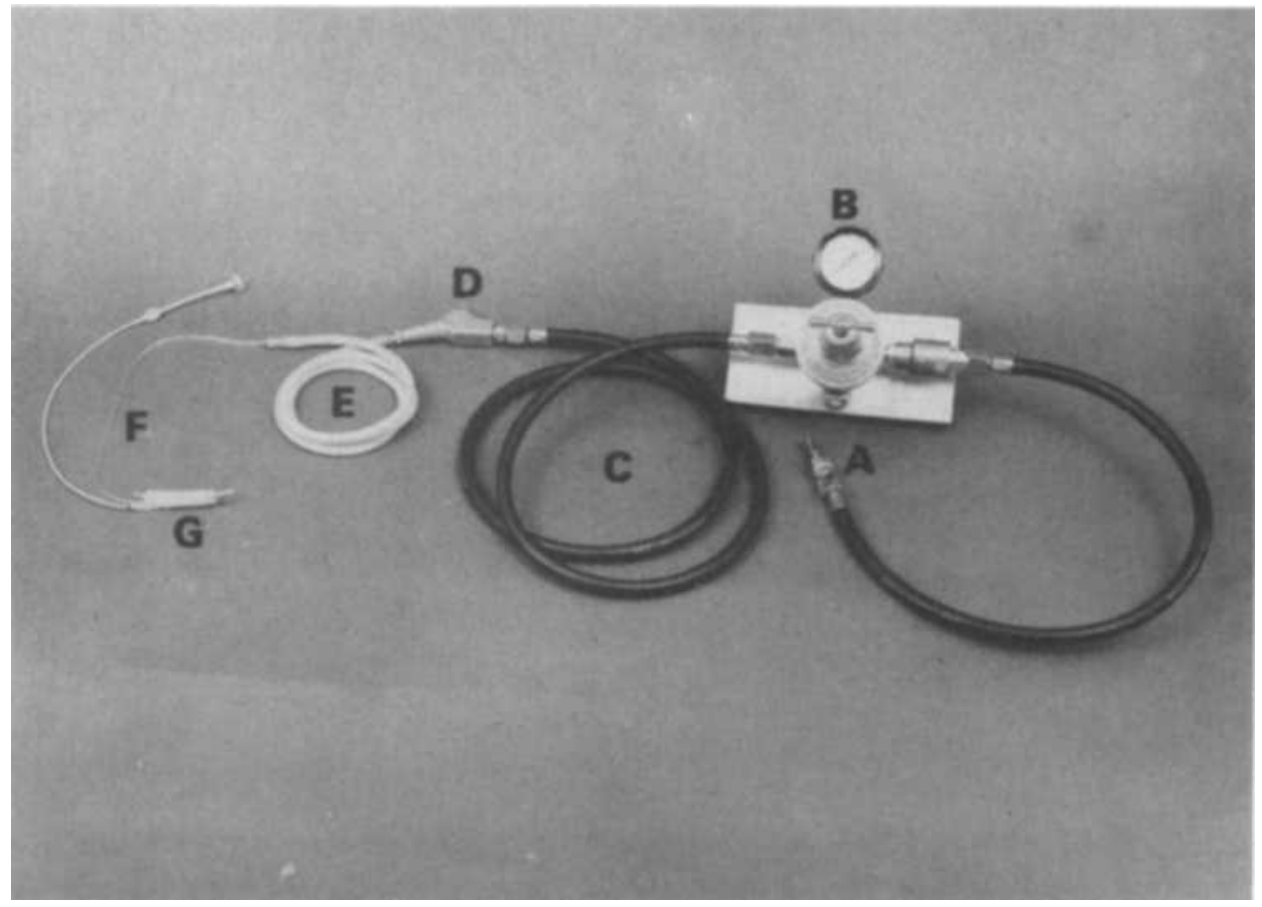

FIGURE 4. The equipment needed to ventilate patients. (A) Schraeder male connector (plugged into pipeline oxygen at 50 PSI) (B) Pressure reducing valve. (C) High pressure hose. (D) Blow gun. (E) Soft rubber hose. (F) Oxygen jet tube. (G) Special tracheal tube.

to flow oxygen intermittently from the jet mounted in the tracheal tube. This was the same as that used for carrying out bronchoscopic ventilation through the sidearm of the bronchoscope ${ }^{5}$ (Figure 4).

This tube was placed in the trachea $1 \%$ inch to 1 inch below the cords with the aid of an obturator (Figure 5 ). The cuff was inflated and by intermittent insufflation of oxygen at high pressures from the oxygen jet sufficient pressure was generated to inflate the lungs intermittently.

\section{EXPERIMENTAL Studies}

The distal end of a special $8 \mathrm{~mm}$ tracheal tube was connected to the apparatus shown in Figure 6, with which flows and pressures could be measured. The proximal end of the oxygen jet tubing was connected to the apparatus seen in Figure 4 and this was then connected to pipeline oxygen at $50 \mathrm{lb}$ per square inch through a Schraeder connector.

First, the clamp was tightened so that no gas could escape from the end of the test device and the pressure reducing valve was adjusted to allow the pressure distal to the valve (i.e., pressure leading to the oxygen jet) to be zero. Then the pressure was increased in increments of $5 \mathrm{lb}$ per square inch while the pressure obtained at the end of the tracheal tube was recorded. The results are seen in Figure 7. 


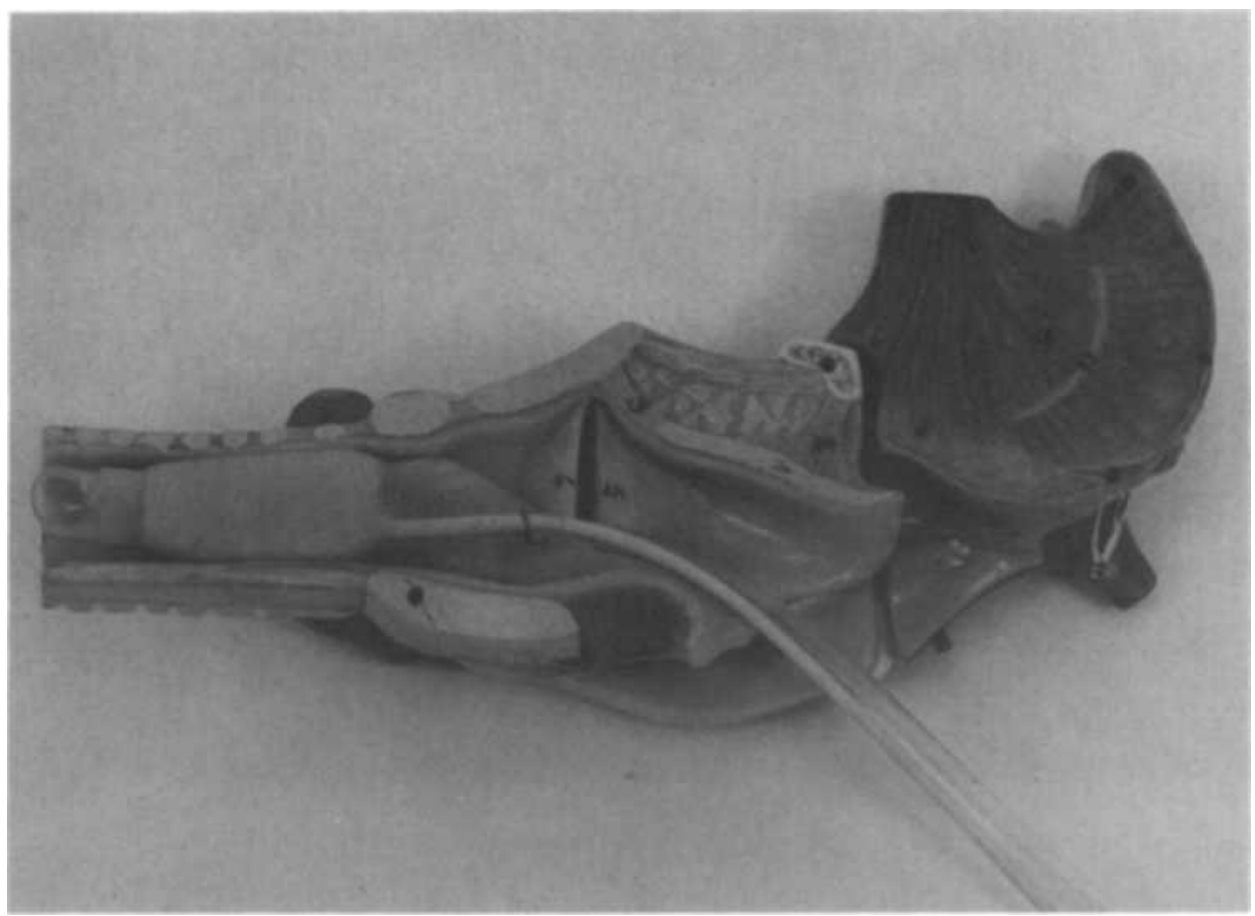

Figure 5. The special tracheal tube in position in the trachea, shown on a model.

The pressure reducing valve was then set to deliver sufficient pressure so that the pressure at the distal end of the tracheal tube (i.e., the pressure available to inflate the patient's lungs) was $20 \mathrm{~cm}$ of water. By opening the clamp, the resistance to flow of gas from this device could be varied. The amount of gas flowing from it was measured on the Wright respirometer and was compared to the number of centimeters of water pressure developed. These experiments were repeated three times with the flow measured for one minute each time. The experiment was then repeated with the pressure reducing valve set to deliver $30 \mathrm{~cm}$ of water pressure from the device. The average results at each reading were taken, and the results are seen in Figure 8.

Next, the pressure reducing valve was adjusted to give delivered pressures of $10,15,20,25$, and $30 \mathrm{~cm}$ of water at the distal end of the tracheal tube. At each particular setting the clamp was opened wide and the proximal end of the tracheal tube was occluded. The oxygen was then allowed to flow and was measured on the Wright respirometer. The oxygen flow from the jet compared to the pressure developed at the distal end of the tracheal tube could be compared. The results are seen in Figure 9.

The device was tested on two dogs anaesthetized with intravenous nembutal and paralyzed with succinylcholine. The device was placed in a position approximately $1 \mathrm{~cm}$ below the cords under direct vision, using a Magill laryngoscope blade and an obturator. The cuff was then inflated and the obturator removed. With the pressure reducing valve adjusted to deliver $20 \mathrm{~cm}$ of water at the end of 


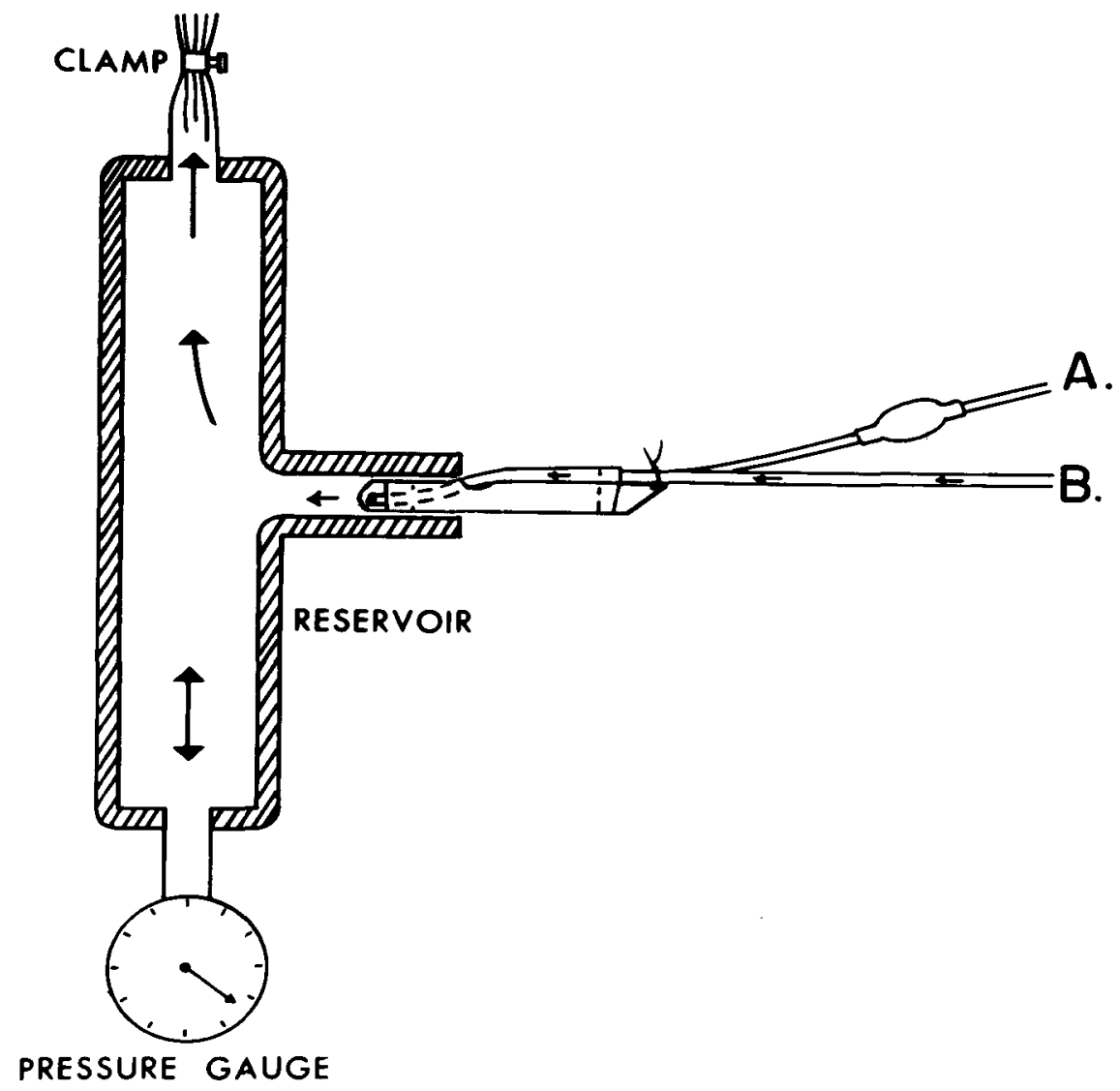

Figure 6. The test equipment required.

the device, the lungs were intermittently inflated by depressing the blow gun button. Arterial carbon dioxide levels in these dogs varied between 30 and $35 \mathrm{~mm}$ of mercury and the oxygen levels between 500 and $550 \mathrm{~mm}$ of mercury. (Samples were taken from a peripheral artery by percutaneous puncture into heparinized syringes and were immediately analyzed on an IL Model 113 blood gas analyzer.) No untoward sequelae were found during these experiments.

\section{Clinical Use}

This system has been clinically tested on twenty-five patients having microsurgery on the larynx. The patients were premedicated with diazepam, $10 \mathrm{mg}$ intramuscularly given one hour before surgery. On the arrival at the operating room an intravenous infusion was started with an 18-gauge plastic cannula and EKG leads connected to the chest giving an EKG readout on an oscilloscope through a VHF telemetry system. ${ }^{6}$ Prior to induction of anaesthesia the tubes which might be used on these patients were first tested by connecting them to the oxygen injector system with the distal end of the tubes introduced into a Racine 


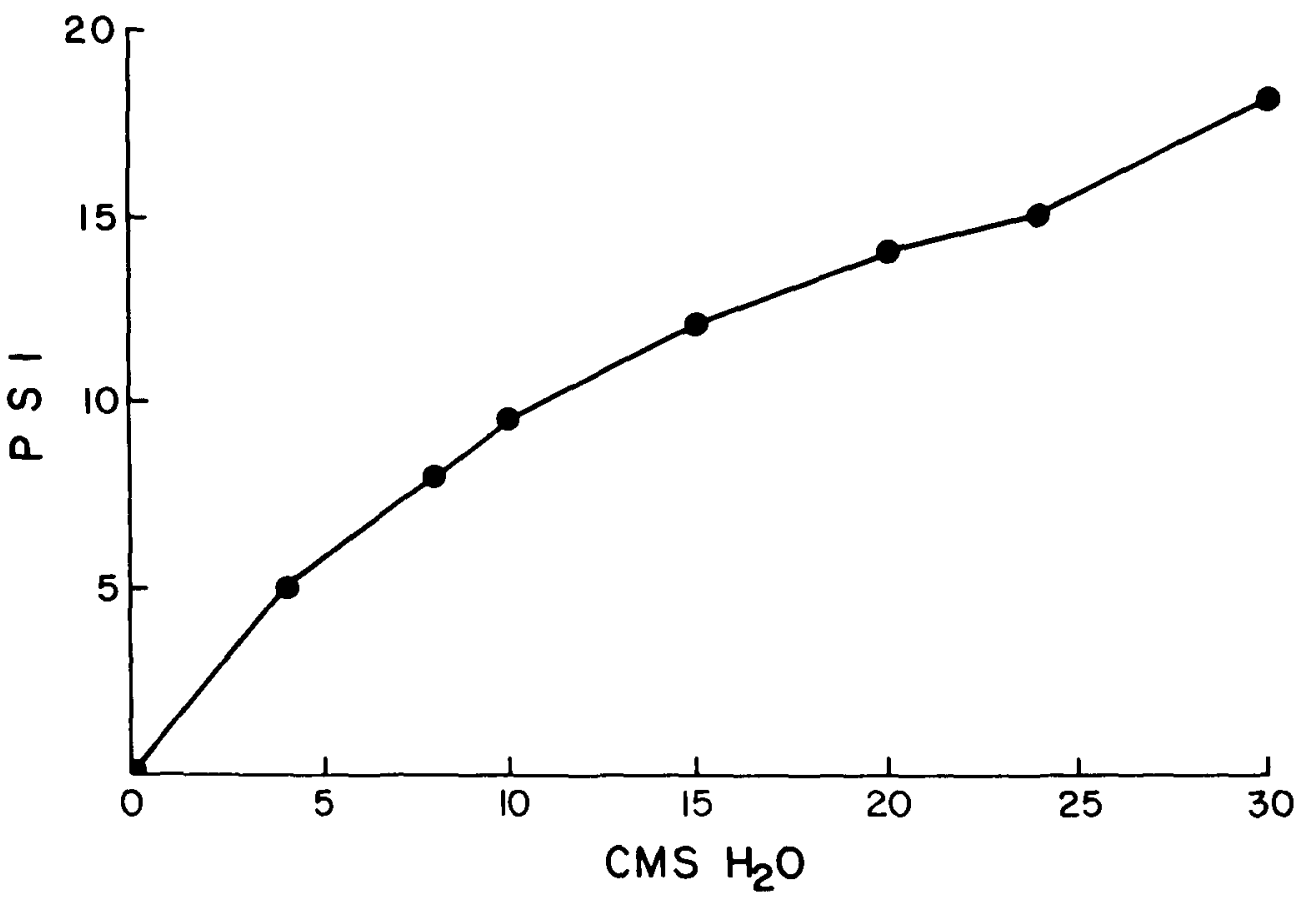

Frgure 7. Pressure at the reducing valve in PSI plotted against cms. of $\mathrm{H}_{2} \mathrm{O}$ pressure developed from the tube $(8 \mathrm{~mm})$.

connector connected to a pressure gauge. (See Figure 10.) Using this as a guide, the pressure developed from the tube was adjusted to $20 \mathrm{~cm}$ of water by adjusting the pressure reducing valve (see Figure 4).

The patients were then pre-oxygenated for four minutes. Induction of anaesthesia was carried out with intravenous methohexitone in a dosage sufficient to ensure adequate hynosis followed by $80 \mathrm{mg}$ of succinylcholine intravenously. Next, under direct vision and using a Macintosh laryngoscope blade, the tube mounted on its obturator ( see Figure 3) was inserted through the cords. (It is well to note at this point that various sizes of tube are always available so that should there be much more distortion of the laryngeal opening than originally thought, a smaller tube will always be at hand for insertion.) The cuff on the tube was then inflated and the obturator was removed. Positive pressure ventilation was begun immediately by intermittently pressing and releasing the blow gun button and the patient was then ready for the attention of the otorhinolaryngologist.

The surgeon then inserted his operating laryngoscope blade and surgery began. A succinylcholine drip of $500 \mathrm{cc}$ of normal saline was begun into the infusion line to ensure relaxation. Further doses of 1 per cent methohexitone in 3 cc increments were given by the same route as needed to ensure hypnosis.

The cuff tube and oxygen jet tube are fitted on the tracheal tube in such a way that when the special tracheal tube is correctly inserted, these two tubes leave the trachea through the cords in the posterior part of the laryngeal opening, causing little or no obstruction to the surgeon's view. In fact, in most cases when viewing 


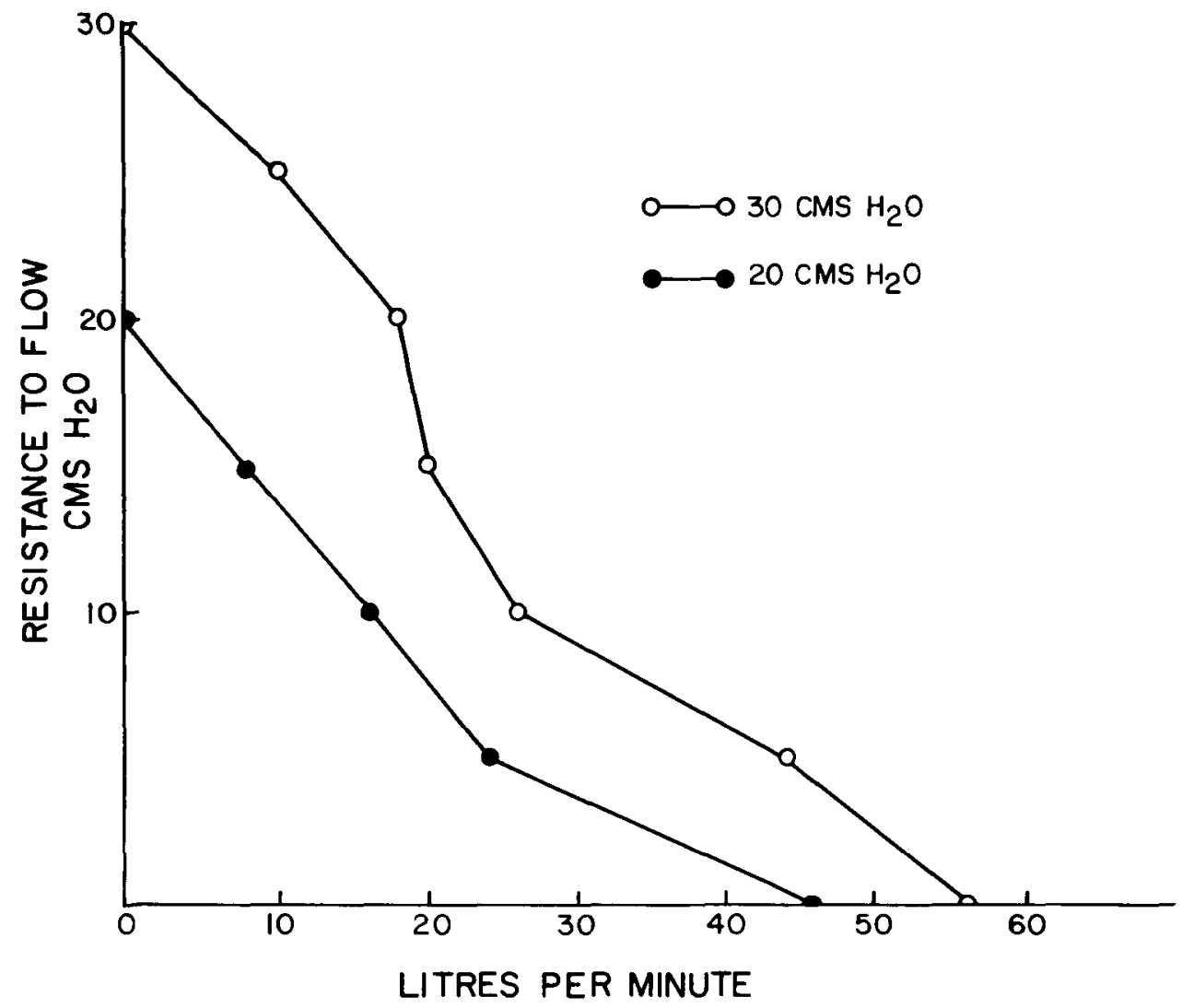

FIGURE 8. Flow in liters per minute coming from the special tracheal tube plotted against resistance to flow with the reducing valve set to deliver pressures of $20 \mathrm{~cm}$ and $30 \mathrm{~cm}$ of $\mathrm{H}_{2} \mathrm{O}$ from the tube.

the cords down the operating microscope it was impossible to see these tubes. It was noted that at all times during both inspiratory and expiratory cycles, gas was escaping through the cords and blood which appeared near the edges of the cords was blown out of the trachea.

Arterial blood samples were taken by percutaneous puncture of the radial artery before and during operation. The results from the first five patients are seen in Table I. When the operation had been completed and following careful suctioning of the back of the throat, the cuff on the tube was deflated. The tube was withdrawn very simply by pressing the blow gun button. This caused a jet of oxygen to flow, which caused a positive pressure in the trachea and very simply blew the tracheal tube out through the cords. Occasionally, slight traction on the two tubes leading from the tracheal tube was needed. An oropharyngeal airway was then inserted, the succinylcholine drip was turned off, and the patient was then gently ventilated with 100 per cent oxygen by mask in a $5^{\circ}$ Trendelenburg position until spontaneous respiration started again.

During one of the operations (a Teflon injection of a non-functioning vocal 


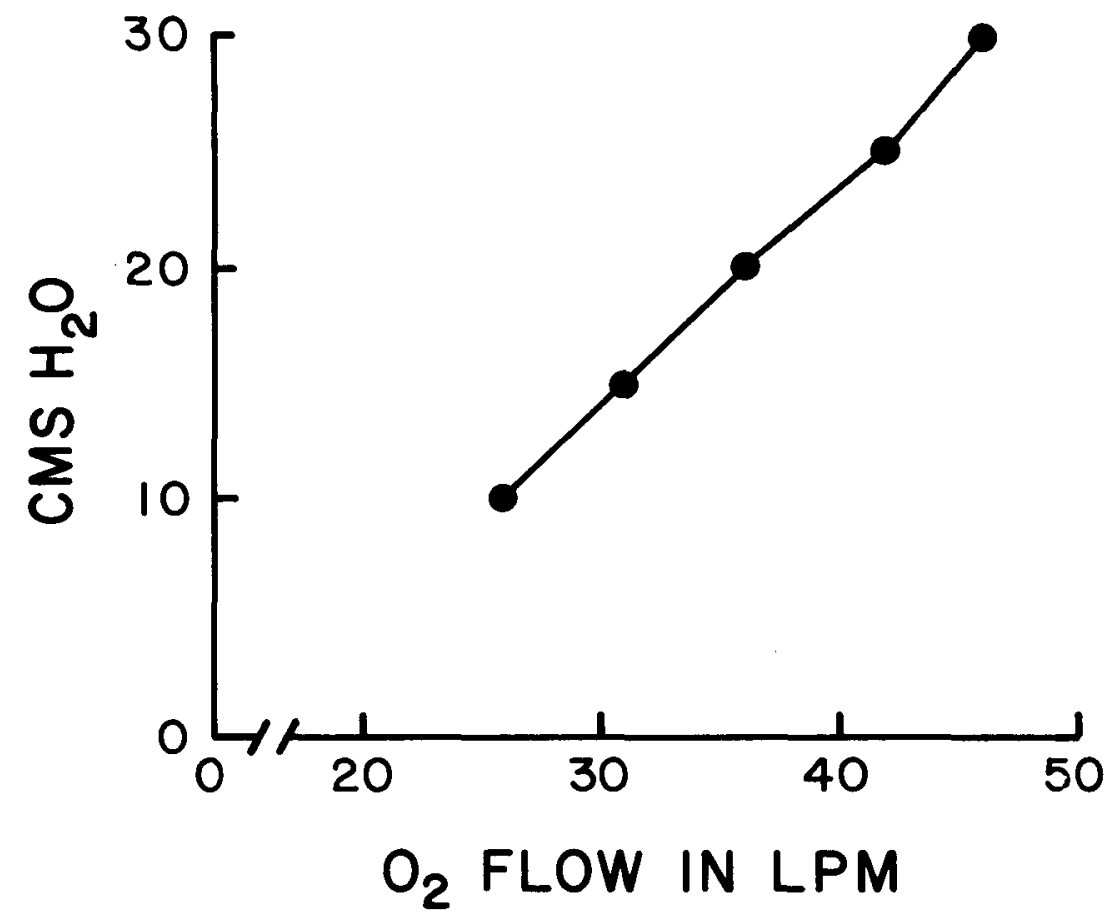

Figure 9. Maximum pressure deliverable from the special tracheal tube plotted against the oxygen flow coming from the jet.

cord), the patient although still asleep under the influence of methohexitone was allowed to regain function of the vocal cords by switching off the succinylcholine drip, so that the surgeons could see how much Teflon to inject to allow correct approximation of the cords. The two small tubes coming out through the cords seemed to not interfere at all with the movement of the free cord.

\section{Results}

It can be seen plainly from studying Figure 7 that very adequate pressures can be produced by this system, enabling positive pressure ventilation to be accomplished easily.

In studying Figure 9, it can be seen that with $20 \mathrm{~cm}$ of water maximum pressure available, an oxygen flow rate of approximately 38 liters per minute would be possible. Also, with the maximum pressure at $30 \mathrm{~cm}$ of water the oxygen flow rate was 48 liters per minute. This, of course, is the oxygen flow only and does not include any air which may have been entrained.

In Figure 8 the pattern of flow into the lungs can be seen for settings of $20 \mathrm{~cm}$ and $30 \mathrm{~cm}$ of water maximum pressure; and it is interesting that with the device set to deliver $20 \mathrm{~cm}$ of water maximum pressure the oxygen flow only is approximately 38 liters per minute (Figure 9), but the total flow from the tube with no resistance to flow, under these conditions, is 46 liters per minute. However, this has 


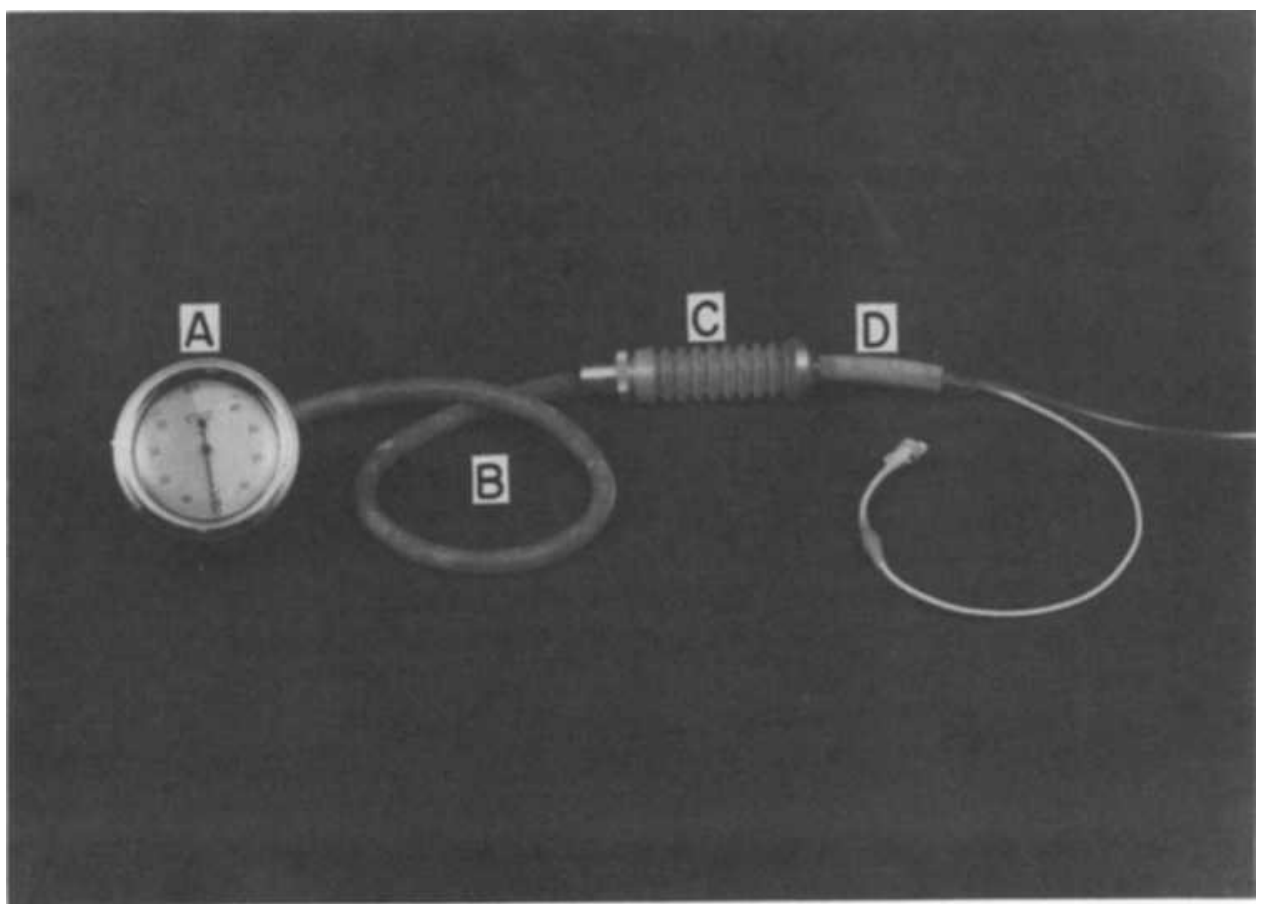

FigURE 10. The apparatus used to test the pressure delivered from the special tracheal tube before use. Shown are: (A) Pressure gauge. (B) Rubber tube connecting to (C) Racine connector in which is fitted (D) Special tracheal tube.

TABLE I

TABLE I. Blood gases in five patients taken whenever possible prior to anaesthesia and then five and ten minutes after the start.

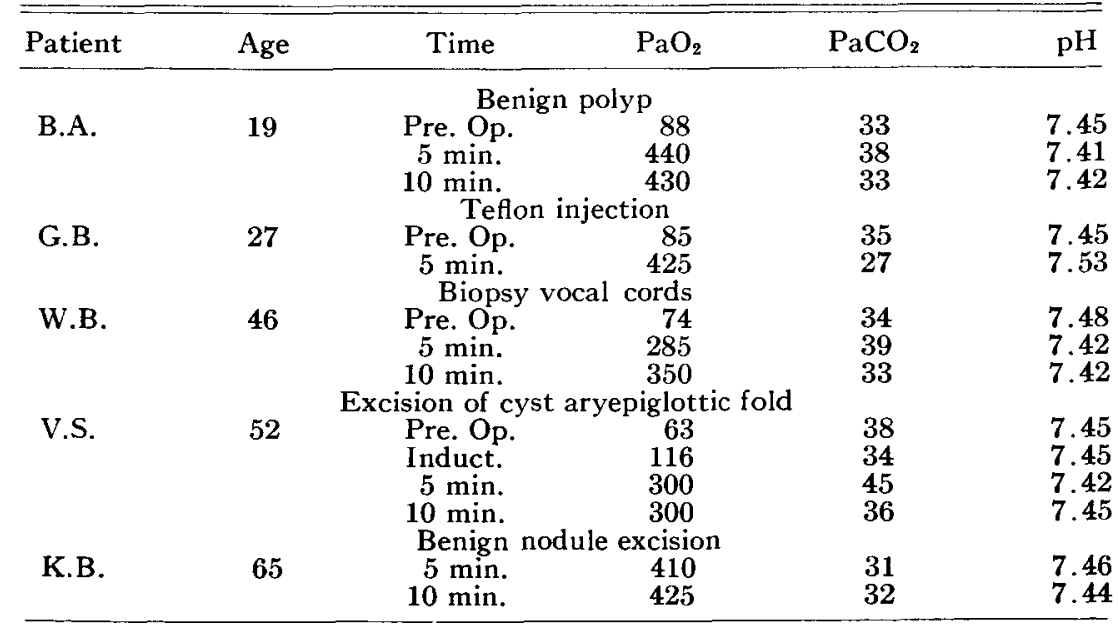


fallen 38 liters per minute by the time the resistance to flow has reached approximately $2 \mathrm{~cm}$ of water. Under clinical conditions, this means that virtually no air entrainment occurs and that at nearly all times in the inspiratory cycle oxygen is blowing back from the tracheal device through the cords, as will be the case during expiration. These results agree with the concept that as the size of the jet is increased, less air entrainment occurs. ${ }^{7,8}$ By referring to Table $I$ it can be seen that blood gas levels are very adequate and oxygen levels are exceedingly high, indicating ventilation of the patient with 100 per cent oxygen or very near it.

\section{Discussion}

We shall first consider this technique of anaesthesia in relation to the safety of the patient. The blood gas levels indicate that the patients are ventilated with approximately 100 per cent oxygen. This means that during the procedure the patient is extremely well oxygenated and, far more important, at the end of the operation the lungs are full of oxygen. This means theoretically that the patient can be apnocic for five minutes without having the arterial $\mathrm{PaO}_{2}$, fall below $100 \mathrm{~mm}$ of mercury."

As can be seen from the results in Table I, this system ensures adequate minute volumes of ventilation. It is possibly more important that increase of ventilating pressure to overcome increases of resistance to ventilation may be provided by merely increasing the pressure delivered from the pressure reducing valve to the tracheal tube. Even laryngeal spasm should not cause much of a problem with this tube in position. It is well known that when laryngeal spasm occurs, it is impossible to ventilate the patient from above the cords using a mask or other form of positive pressure applied to the upper airway. This is because the larynx is shaped in such a way that pressure from above tends to close the cords even tighter together. However, pressure from below tends to blow the cords apart and, in fact, it should be possible to ventilate with an adequate minute volume even though the cords have gone into spasm because the pressure from below will tend to blow the cords apart and gas will escape from the lungs. Constant monitoring of the degree of relaxation of the cords is carried out by the surgeon and if the relaxant is allowed to wear off for a short time, as in the case we have described, then ventilation is stopped momentarily until the cords are paralyzed again, or continued at a lower pressure allowing longer for expiration to occur to minimize the possible hazard of lung damage.

Apnoeic techniques and the use of the venturi principle have the hazard of inhalation of blood and debris. In this technique, for practically the whole inspiratory cycle, gas is blowing out through the cords and so minimizing this problem. It was found that the optimum way to ventilate patients with blood or debris in the area of the glottic was to follow expiration by the inspiratory phase without appreciable pause, in order to continue the flow of gas out through the cords and so to prevent inhalation.

Operating conditions are generally found to be extremely good because of complete relaxation and the lack of obstruction to the surgeon's operating field. If the surgeon wishes to operate on the posterior part of the cords, then it is a very simple matter to put the tracheal tube into position rotated through $180^{\circ}$. 
It would seem that this technique ensures great safety for the patient and almost perfect operating conditions for the surgeon. This combination of factors would seem to be unique in the field of anaesthesia for microlaryngeal surgery.

\section{RÉSUMÉ}

Nous décrivons une technique pour la microchirurgie laryngée. Par cette technique, l'anesthésie est produite par des barbituriques donnés par voie endoveineuse ainsi que les myorésolutifs et un jet d'oxygène est administré à travers un tube endotrachéal à ballonnet de $2 y_{2}^{\prime \prime}$ de long placé de $\frac{1 / 2}{2}$ à 1 pouce sous les cordes vocales et maintenu en position en gonflant le ballonnet. L'insufflation intermittente du jet d'oxygène produit un gonflement intermittent des poumons sans entraîner d'air. L'expiration passive se fait et par le tube et entre les cordes durant la phase expiratoire. Les avantages de cette technique sont que les seules obstructions dans le champ opératoire du chirurgien sont le tube du jet d'oxygène et le tube qui sert à gonfler le ballonnet. Ces deux tubes sont petits et maintenus en position fixe. La ventilation se fait avec de l'oxygène à 100 pour cent à une pression connue assurant ainsi une grande sécurité et durant les deux phases : inspiratoire et expiratoire, les gaz sortent de la glotte évitant ainsi que les débris se dirigent vers les poumons.

\section{ACKNOWLedGMents}

The authors wish to thank Mr. Billy Baity for his technical help in the making up of the equipment to carry out these experiments, Miss Betty Billings from the Department of Medical Illustrations, North Carolina Memorial Hospital, and Dr. Newton Fischer, Professor of Surgery in Otorhinolaryngology, North Carolina Memorial Hospital, Chapel Hill, for allowing us to use this technique on patients under his care.

\section{REFERENCES}

1. Rajagopalan, R., Smith, F., \& Ramachandran, P.R. Anesthesia for microlaryngoscopy and definitive surgery. Canadian Anesthetists' Society Journal. 19: 83-86 (1972).

2. Oulton, J.L. \& DonALD, D.M. A ventilating laryngoscope. Anesthesiology 35: 540-542 (1971).

3. Spoerel, W.E., Narayanan, P.S., \& Sugi, N.P. Transtracheal ventilation. British Journal of Anesthesia 43: 932-938 (1971).

4. Spoerel, W.E. \& Greenway, R.E. Anaesthetic technique for endolaryngeal surgery. A.S.A. 1972. (October).

5. Carden, E., Oulton, J.L., \& Trap, W. Ventilation system for patients undergoing bronchoscopy. Anesthesiology 33: 454-458 (1970).

6. Davis, D.A. \& Thornton, W.E. Radio telemetry in anesthesia and surgery. Electronics in Anesthesiology-International Anesthesiology Clinics. 3: 535-545 (1965).

7. Carden, E. Positive pressure ventilation during anesthesia for bronchoscopy. Anesthesia and Analgesia. In press.

8. Spoerel, W.E. Personal Communication (1972).

9. Cole, W.L. \& Stoelting, V.K. Blood gases following induction with two types of oxygenation. Anesthesia and Analgesia. 50: 68-72 (1971). 